LISBOA, TURIM E O INTERCÂMBIO

CULTURAL DO SECELO DAS LUZES

A EUROPA PÓS-NAPOLEÓNICA

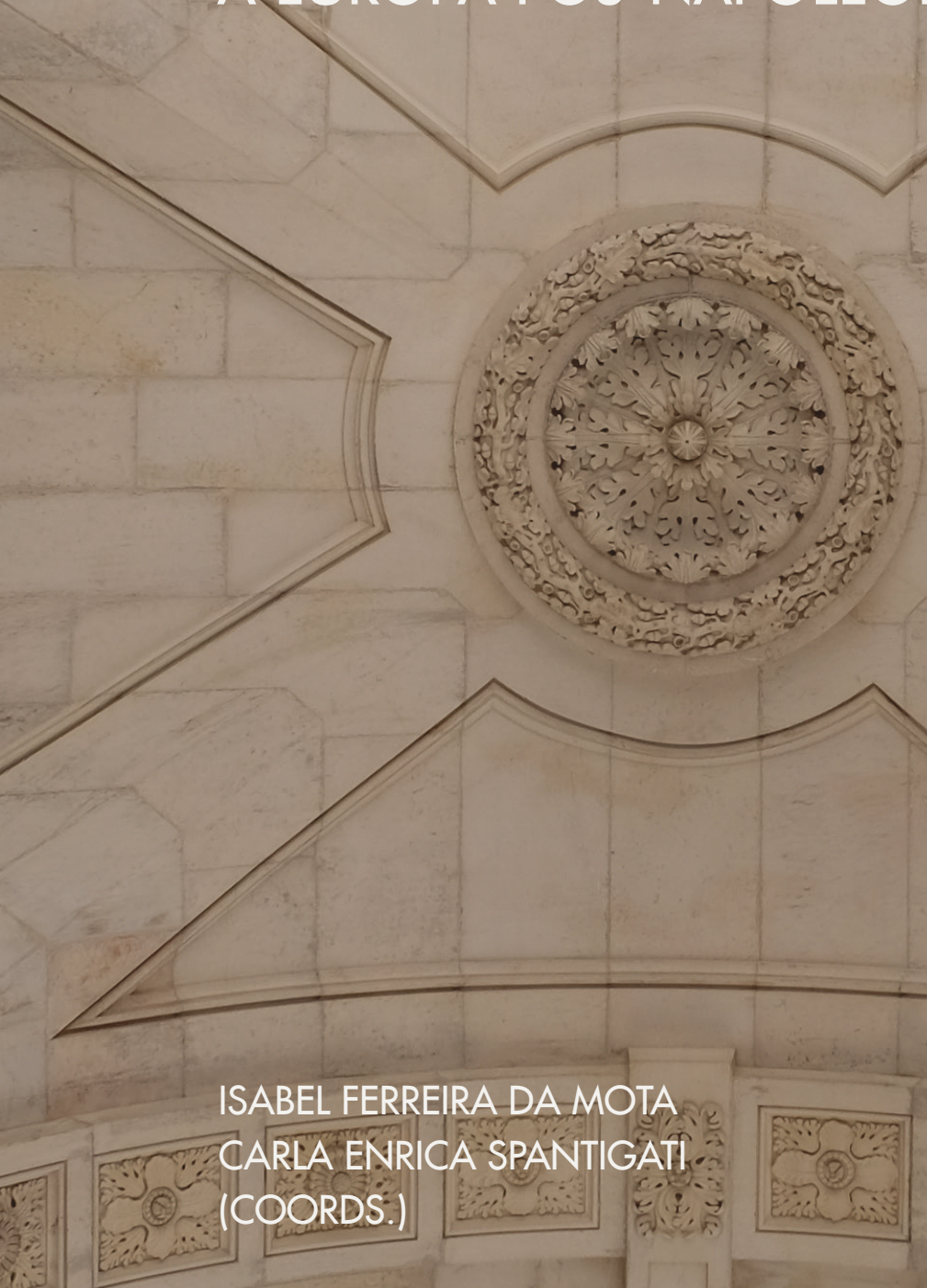

IMPRENSA DA

UNIVERSIDADE

DE COIMBRA

COIMBRA

UNIVERSITY

PRESS

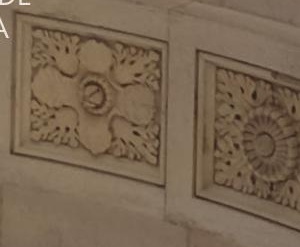


Assente numa abordagem interdisciplinar, este volume fornece uma perspectiva-plurifacetada sobre um período particularmente importante da constituição e recomposição da geografia artístico-cultural e política europeia, na transição do sécŭlo XVIII para o século XIX. Elege como foco de análise as relações entre Lisboa e Turim e a sua exemplaridade no âmbito das formas de sociabilidade e circulação de objectos, saberes, gostos, estilos de governo e políticas públicas, sobre as quais se construiu o panorama geopolítico europeu e mesmo a sua projecção nos impérios. Sendo múltiplas as abordagens ao tema em apreço, - que as une é uma concepção alargada de cultura e história cultural, que vai da cultura-visual à cultura científica, da cultura material à cultura política. As ligaçóes estabelecem-se na infraestrutura das sensibilidades e na transferência dos gostos e dos habitus. 


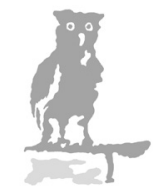

$\begin{array}{lllllllllllll}\text { I } & \mathrm{N} & \mathrm{V} & \mathrm{E} & \mathrm{S} & \mathrm{T} & \mathrm{I} & \mathrm{G} & \mathrm{A} & \mathrm{C} & \tilde{\mathrm{A}} & 0\end{array}$

IMPRENSA DA UNIVERSIDADE DE COIMBRA

COIMBRA LNIVERSITY PRES

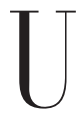




\section{EDIÇÃo}

Imprensa da Universidade de Coimbra Email: imprensa@uc.pt

URL: http//www.uc.pt/imprensa_uc

Vendas online: http://livrariadaimprensa.uc.pt

COORDENAÇÃO EDITORIAL

Imprensa da Universidade de Coimbra

CONCEÇÃo GRÁFICA

Imprensa da Universidade de Coimbra

IMAGEM DA CAPA

Julien Chatelain from Paris, France [CC BY-SA 2.0

(https://creativecommons.org/licenses/by-sa/2.0)]

\section{INFOGRAFIA}

Bookpaper

EXECUÇÃo GRÁFICA

Simões e Linhares, Lda.

ISBN

978-989-26-1738-1

ISBN DIGITAL

978-989-26-1739-8

DOI

https://doi.org/10.14195/978-989-26-1739-8

DEPÓSITO LEGAL

460666/19

C SETEMBRO 2019, IMPRENSA DA UNIVERSIDADE DE COIMBRA

SIMÃO, Licínia, e outro

O multilateralismo : conceitos e práticas no séc. XXI

/ Licínia Simão, Sandra Fernandes. - (Investigação)

ISBN 978-989-26-1749-7 (ed. impressa)

ISBN 978-989-26-1750-3 (ed. eletrónica)

I - FERNANDES, Sandra

CDU 327 
TANTO ELLA ASSUME NOVITATE AL FIANCO

LISBOA, TURIM E O INTERCÂMBIO CULTURAL DO SÉCULO DAS LUZES À EUROPA PÓS-NAPOLEÓNICA

ISABEL FERREIRA DA MOTA CARLA ENRICA SPANTIGATI (COORDS.)
IMPRENSA DA

UNIVERSIDADE DE COIMBRA

COIMBRA

UNIVERSITY

PRESS 
(Página deixada propositadamente em branco) 


\section{S U M Á R I O}

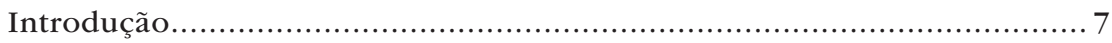

Isabel Ferreira da Mota e Carla Enrica Spantigati

D. Rodrigo de Sousa Coutinho em Turim: cultura económica

e formação política de um diplomata ilustrado .

José Luís Cardoso

Turim-Lisboa 1769-1796. O olhar dos embaixadores

49

Gian Paolo Romagnani

Da viagem à Itália à prática institucional e política:

entre Turim e Lisboa

Isabel Ferreira da Mota

Ciência, Diplomacia e Viagem: Dom Rodrigo de Souza Coutinho

e o tour mineralógico dos savants luso-brasileiros José Bonifácio

de Andrada e Silva e Manoel Ferreira da Câmara Bithencourt

em Turim...

Junia Ferreira Furtado

Vincenzo Belli (1710-1787). Percurso de um ourives: um turinês em Roma que trabalhou para Lisboa

Teresa Leonor M. Vale 
De Lisboa a Turim. Porcelanas e "casse di vernice della Cina» para o ministro plenipotenciário Carlo Francesco II Valperga di Masino

Cristina Mossetti, Lucia Caterina, Sabrina Beltramo, Laura Tos, Corrado Trione

Giuseppe Trono em Portugal: Um pinto de retratos piemontês entre monarquia e revolução (1785-1810).

Giuseppina Raggi, Michela Degortes

A arte na mala diplomática

Carla Enrica Spantigati

Luigi Cinatti e os "ammodernamenti" de Palagi nas residências da Casa de Saboia

Monica Tomiato

Fontes e documentos sobre as relações musicais entre Turim

e Lisboa na segunda metade do século XVIII 359

Annarita Colturato

Il furioso nell'Isola di San Domingo de Donizetti: o percurso de uma opera semisseria na época romântica entre Itália e Portugal.... 393 Luísa Cymbron

Lista onomástica. 421 


\title{
D. RODRIGO DE SOUSA COUTINHO EM TURIM: CULTURA ECONÓMICA E FORMAÇÃO POLÍTICA DE UM D I PLOMATA ILUSTRADO
}

\author{
José Luís Cardoso \\ Instituto de Ciências Sociais \\ Universidade de Lisboa
}

\section{Introdução}

No dia 23 de Setembro de 1779, D. Rodrigo de Sousa Coutinho chegou a Turim para iniciar a sua missão como Enviado Extraordinário e Ministro Plenipotenciário no reino da Sardenha que, entre os seus territórios mais importantes, incluía o Ducado de Saboia e o Principado do Piemonte. Seis dias depois apresentou credenciais ao rei Vitor-Amadeu III. ${ }^{1}$

A nomeação oficial tinha ocorrido mais de um ano antes, por despacho de 13 de Setembro de 1778. Partiu de Lisboa no final de Outubro desse ano e demorou-se em Madrid até final de Janeiro de 1779, visitando o seu pai Francisco Inocêncio de Sousa Coutinho que então exercia o cargo de Embaixador de Portugal

${ }^{1}$ As anotações biográficas aqui registadas seguem o estudo monumental de MANSUY-DINIZ SILVA A. (2002-2006), Portrait d'un homme d'État: D. Rodrigo de Souza Coutinho, Comte de Linhares, 1755-1812. Paris: Centre Culturel Calouste Gulbenkian, Vol. I e Vol. II. 
na corte espanhola. Foi certamente útil esta estada, tendo em vista a preparação do seu futuro percurso diplomático. Em Abril de 1779 chegou a Paris, infletindo o trajeto geográfico que o destinava a Turim, capital piemontesa e do reino da Sardenha. Mas esse détour foi pródigo em contactos estabelecidos, havendo registos ou testemunhos dos seus encontros com Raynal, Laplace, Lagrange e d'Alembert, entre outros representantes da França ilustrada. Foi também nessa ocasião que manteve contacto próximo com António Ribeiro Sanches, médico e cientista português de reputação internacional que, devido à sua confissão judaica, vivia exilado em Paris.

No início de Agosto deixou Paris em direção a Turim, com diversas paragens pela Suiça, designadamente em Genève. A correspondência familiar e os apontamentos e diários desta longa jornada que o levou de Lisboa a Turim oferecem informações preciosas sobre as cogitações intelectuais e políticas de um jovem de 23 anos que deliberadamente se preparava para o exercício de cargos públicos cuja importância antecipava de forma clarividente. O mundo europeu da ciência, da literatura, da filosofia e da política revelava-se nas passagens e paragens que o conduziam à corte da Sardenha. Conheceu pessoas ilustres e juntou livros que viriam a formar a base da sua rica biblioteca.

O início da missão diplomática foi perturbado pela morte de seu pai, em Março de 1780, que o obrigou a voltar a Lisboa para resolução de assuntos familiares. Só regressaria a Turim a 26 de Agosto de 1782, para a partir de então assumir a plenitude do seu cargo, que manteria até 30 de Julho de 1796, data do seu retorno definitivo a Lisboa para se ocupar da chefia do Ministério e Secretaria de Estado da Marinha e Domínios Ultramarinos. Este e os outros cargos políticos que viria a cumprir durante a regência e reinado de D. João VI, quer em Lisboa, quer no Rio de Janeiro, beneficiaram largamente da experiência que adquiriu e acumulou durante a 
estadia no Piemonte. ${ }^{2}$ O propósito deste texto é, justamente, o de assinalar o carácter decisivo e fundamental desses anos de formação, que foram também anos de exercício de diplomacia, sobretudo no terreno económico.

Começarei por apresentar e analisar os principais textos que escreveu durante a sua estadia em Turim, mostrando como são indiciadores de preocupações económicas e financeiras que viriam a revelar alguma persistência ao longo da sua carreira política. Seguidamente, procurarei enquadrar as linhas definidoras do seu pensamento económico à luz das reflexões produzidas e das medidas de ação preconizadas pelos autores que marcaram a formação da economia política da Ilustração europeia, reclamando para D. Rodrigo de Sousa Coutinho um lugar de destaque entre os seus pares. Grande parte da argumentação a utilizar baseia-se no legado que nos é transmitido pelas estantes da biblioteca que constituiu durante o tempo que permaneceu em Turim, cujos livros encerram ensinamentos que soube utilizar e adaptar de forma inovadora.

${ }^{2}$ Após regressar de Turim, D. Rodrigo exerceu sucessivamente os cargos de Ministro e Secretário de Estado da Marinha e Domínios Ultramarinos (1796-1801), Presidente do Real Erário e Ministro e Secretário de Estado da Fazenda (1801-1803) e Ministro da Guerra e dos Negócios Estrangeiros (1808-1812). Foi-lhe atribuído o título de Conde de Linhares em 1808. O seu nome está indissociavelmente ligado a todos os acontecimentos políticos, económicos, sociais e culturais que ocorreram em Portugal durante a regência e reinado de D. João VI, até à sua morte em 1812. $\mathrm{O}$ presente texto apenas aborda a primeira etapa da sua carreira política. Para uma abordagem integrada do seu pensamento económico e político, cf. José Luís Cardoso, O pensamento económico em Portugal nos finais do século XVIII. Lisboa: Estampa, 1989; e José Luís Cardoso, Nas malhas do império: a economia política e a política colonial de D. Rodrigo de Sousa Coutinho. In J. L. Cardoso (org.), A economia política e os dilemas do Império Luso-Brasileiro (1790-1822). Lisboa: Comissão Nacional para a Comemoração dos Descobrimentos Portugueses, 2001, 63-109. 


\section{Recopilações, discursos e reflexões}

O zelo e cuidado que D. Rodrigo emprestava à sua missão diplomática em Turim ficam claramente demonstrados nos balanços anuais da sua atividade, dos quais se conservam registos relativos aos anos de 1783 a $1786.3^{3}$ Estas recopilações anuais dos ofícios enviados semanalmente ao Ministro e Secretário de Estado dos Negócios Estrangeiros oferecem testemunho inequívoco do empenho político com que encarava e praticava o seu ofício de ministro plenipotenciário na Corte da Sardenha. Não se trata de simples registos burocráticos das rotinas de um representante diplomático que se sentisse forçado à prestação de contas. São documentos que apresentam uma narrativa organizada de matérias que suscitavam uma reflexão amadurecida, nas quais D. Rodrigo de Sousa Coutinho espreita a oportunidade para expressar o seu ponto de vista sobre o que de mais relevante estava em jogo no exercício do seu cargo. A organização do exército e a reforma das instituições eclesiásticas, o funcionamento do sistema de justiça e dos tribunais, questões relativas à educação pública e às políticas sociais relacionadas com a saúde pública e o controlo da mendicidade, ou ainda os problemas da ordem internacional e da disputa entre nações, são alguns dos assuntos que aborda nas suas recopilações. Mas são sobretudo os temas de índole económica e financeira - sobre a organização e dinâmica dos diversos setores de atividade económica, sobre os sistemas de circulação monetária e de crédito público, sobre a organização das finanças do Estado e política fiscal - os que lhe merecem rela-

3 Arquivo Nacional Torre do Tombo, Fundo do Ministério dos Negócios Estrangeiros, Legação de Portugal em Turim, Caixas 861 a 864, anos 1783 a 1786. Duas destas recopilações foram transcritas e editadas por MANSUY-DINIZ SILVA A. em: COUTINHO D. R. S. (1993), Textos políticos, económicos e financeiros (1783-1811). Lisboa: Banco de Portugal (Colecção de Obras Clássicas do Pensamento Económico Português), Tomo I, 5-93. 
ção mais circunstanciada e que, também por isso, são aqui objeto de privilegiada atenção.

A exposição sobre problemas económicos e financeiros é acompanhada, de forma implícita ou explícita, por uma atitude de emulação e apelo ao seguimento de boas práticas que constata existirem no Piemonte ou noutras áreas geográficas que conhecia. Esta é a postura típica de um político cosmopolita e ilustrado que sabe que a riqueza e grandeza económica e política de uma nação também se promove através da aprendizagem de bons exemplos e de casos bem sucedidos. Afinal, D. Rodrigo queria aproveitar de forma útil as vantagens que a sua estadia em Turim proporcionava, reconhecendo que: "No número das obrigações prescritas a um Ministro que reside em uma Corte estrangeira, talvez nenhuma mais interessante do que a de dever informar do actual estado em que se acha o mesmo país, e dos motivos que seguram a sua prosperidade ou a sua decadência". ${ }^{4}$

Na Recopilação de 1783 surge, como motivo de destaque, um dos assuntos que mais intensamente mobilizou economistas e políticos de diversas proveniências geográficas europeias e de diferentes afiliações doutrinais: a questão da liberdade de comércio dos cereais. Em causa estava a questão de saber qual a orientação política mais adequada à diminuição do preço de bens de consumo essenciais à manutenção da população. E essa questão suscitava um amplo leque de matérias diretamente implicadas: como melhorar a produtividade dos terrenos agrícolas para garantir acréscimos da produção interna? Como melhorar os circuitos de comercialização por forma a evitar oneração excessiva do preço devido a elevados custos de transporte e fortes cargas tributárias? Como impedir, ou facilitar, a entrada de cereais obtidos no estrangeiro a preços mais vantajosos? Quais as consequências no plano social e político de uma política de livre-

${ }^{4}$ COUTINHO R. S., Reflexões políticas.... In Textos políticos, económicos e financeiros, Tomo I, 141. 
-câmbio? Quais os interesses económicos e políticos em jogo e como garantir o seu adequado equilíbrio?

Foram muitos os panfletos e manifestos, foram intensas as polémicas e ofensivas discursivas em torno destas matérias em diversos quadrantes europeus. D. Rodrigo de Sousa Coutinho estava atento a estes debates, conforme se comprova pelos livros existentes na sua biblioteca pessoal, na sua maior parte constituída quando se encontrava em Turim. ${ }^{5}$ Entre as obras de carácter económico com implicações diretas na discussão do tema da liberdade de comércio dos cereais (ou do trigo, como simplificadamente se dizia na época) que constam do Catálogo elaborado no final de 1791 ou início de 1792, refiram-se os livros de Herbert, Dupont de Nemours, Forbonnais e, muito especialmente, os de Galiani e Necker. Olhando retrospetivamente para os debates que inflamaram em especial a opinião pública francesa, o único autor ausente da biblioteca de D. Rodrigo é Turgot, cuja obra reformadora, porém, revelou conhecer e aplaudir (designadamente no que se refere ao plano de reforma administrativa e municipal executado por Turgot em França nos finais da década de 1770), possuindo na sua biblioteca as biografias de Turgot feitas por Condorcet e Dupont de Nemours.

Este debate sobre matérias de política comercial é visto na história do pensamento económico como momento crucial para a construção de argumentos em favor dos méritos de uma economia de mercado em que as instituições e agentes económicos afirmam a necessidade e vontade de se libertarem da tutela do Estado. Momento esse em

\footnotetext{
5 Sobre a constituição e conteúdo global da biblioteca de D. Rodrigo de Sousa Coutinho, cf. CAROLINO L. M. (2013), O poder dos livros. A biblioteca de Rodrigo de Sousa Coutinho. Revista do Instituto Histórico-Geográfico Brasileiro, a. 174 (460), 109-140. O catálogo da biblioteca conserva-se no Arquivo Nacional Torre do Tombo, Fundo Condes de Linhares, Livro 4, acessível em: http://digitarq.arquivos. pt/details?id=4727614. Para se compreender melhor a importância dos livros de economia que integram a sua biblioteca - aos quais faremos frequentes referências ao longo do presente texto - inclui-se no final um Apêndice com a listagem dos livros sobre temas económicos.
} 
que, em contrapartida, o Estado é chamado a assumir um papel de instrumento regulador do livre jogo de tais agentes no mercado, devido à incapacidade demonstrada para, por si sós, promoverem a realização do interesse público. ${ }^{6}$ Liberalismo mitigado ou protecionismo moderado, qualquer que seja a etiqueta que defina o ambiente doutrinal e político deste período, não há dúvidas sobre a sua relevância para a construção do ideário ilustrado da ciência da economia política. ${ }^{7}$

Qual a posição assumida neste debate por D. Rodrigo de Sousa Coutinho? Foi inequívoca a sua firme oposição a práticas restritivas e monopolistas que originavam acréscimo de preço dos cereais, esclarecendo que:

"Não pude deixar de fazer ver o mau efeito de algumas destas providências que oprimindo o livre comércio dos grãos no interior do Estado impediam os negociantes de especularem sobre este ramo de comércio, deixando assim o Estado exposto a maior parte do tempo a sofrer grandes faltas logo que o ano era estéril, quando pelo contrário, se este comércio fora inteiramente livre, a concorrência procuraria certamente o bom e abundante mercado e destruiria igualmente o monopólio". ${ }^{8}$

\footnotetext{
${ }^{6}$ Para uma apreciação de conjunto do contexto histórico deste debate e das lutas políticas em que se insere, cf. KAPLAN S. (1976), Bread, politics and political economy in the reign of Luís $X V$. The Hague: Martinus Nijhoff. Uma análise resumida da importância deste debate na história do pensamento económico é dada por FACCARELLO G. (1994), Nil repente! Galiani and Necker on economic reforms. The European Journal of the History of Economic Thought, 1:3, 519-550.

7 Sobre a noção de economia política ilustrada frequentemente utilizada ao longo deste texto, cf. CARDOSO J. L. (2015), Liberalism and enlightened political economy. The European Journal of the History of Economic Thought, 22:6, 949-977.

8 COUTINHO R. S., Recopilação dos ofícios expedidos de Turim em 1783. In Textos políticos económicos e financeiros, Tomo I, 9.
} 
Advogando uma intervenção do Estado de modo a permitir importação de cereais que garantisse a fixação de um preço baixo, D. Rodrigo remata o seu raciocínio expressando um ponto de vista semelhante ao defendido por Galiani e Necker a propósito do mesmo problema. Ou seja:

"Convindo primeiramente da dificuldade de combinar o preço cómodo que deseja o manufactureiro com o alto preço em que se interessa o agricultor, mostrei que estava persuadido, que toda a legislação sobre os trigos, que se não limitava à perfeita liberdade de comércio, e concorrência no interior do Estado, à permissão de exportação enquanto não chega ao preço que já principia a ser forte para o sustento do jornaleiro, e ao prémio para a importação quando é excessivamente caro, era viciosa em lugar de ser útil ao Estado".?

Em conclusão, ao advogar maior liberdade de ação dos agentes privados no mercado, D. Rodrigo não excluía, antes considerava fundamental, a intervenção reguladora do Estado através de instrumentos de política comercial externa que lhe cabia promover. E em abono dos seus argumentos evoca a autoridade de "homens de peso e consideração", designadamente Necker, Smith e Postlethwayt, de cujas obras dispunha na sua biblioteca.

Nas matérias expostas na Recopilação de 1783, a questão do funcionamento do mercado interno é ainda aflorada quando se refere ao papel dos canais de navegação e de novas estradas que sulquem o território de modo a tornar mais rápidos e menos dispendiosos os circuitos de comercialização.

\footnotetext{
${ }^{9}$ Ibid, 9.
} 
"As providências que interessam imediatamente a agricultura (...) tiveram por objecto, ou o melhoramento das estradas que são as veias do corpo político, e sem as quais a agricultura e a indústria, e o comércio e circulação interior não podem prosperar, ou a legislação do pão, de que tão essencialmente depende a boa cultura das terras, sendo certo que ninguém cultiva quando do seu trabalho não espera colher um fruto considerável". ${ }^{10}$

Este tema da oneração excessiva dos produtos através de custos indiretos de natureza fiscal merece-lhe ainda nova chamada de atenção quando numa das Recopilações de ofícios enviados de Turim aborda o tema do desenvolvimento manufatureiro no Piemonte, especialmente num dos setores que era do seu agrado particular e que procurava conhecer melhor, na expectativa do seu apetrechamento e desenvolvimento em Portugal: a manufatura das sedas.

Para comprovar a relevância que o assunto lhe merecia, vejam-se as Reflexões políticas sobre os meios de criar e fundar solidamente em Portugal a cultura e manufactura da seda (1784). ${ }^{11} \mathrm{D}$. Rodrigo dá amplo destaque a matérias propedêuticas e técnicas, demonstrando a sua faceta de diplomata interessado nos processos de produção e na aplicação de conhecimentos científicos a objetos de utilidade económica e social. A descrição dos métodos de cultivo das amoreiras, de criação de bichos da seda, da extração, fiação e manufatura da seda, revelam a atenção prestada à organização, que conhecia de experiência e contacto direto, do modo como no Piemonte se operava esta fileira produtiva, de cujo nexo dependia o sucesso deste setor industrial. Assim, a proposta de contratação de artífices qualificados e de importação de tecnologia adequada, ou a proposta de criação

\footnotetext{
${ }^{10} \mathrm{Ibid}, 56$.

11 Incluídas in COUTINHO R. S., Textos políticos, económicos e financeiros, Tomo I, 113-131.
} 
de instrumentos fiscais e condições financeiras para incentivar a produção de tecidos de seda em Portugal, era fruto do empenho direto em concretizar um plano industrial inspirado na experiência piemontesa. E a verdade é que os seus esforços de diplomata imbuído da missão de promotor industrial tiveram resultados concretos e comprovados pela instalação em Chacim, Trás-os-Montes, da família piemontesa Arnaud, atraída para o desenvolvimento de um negócio rentável. O patrocínio e apoio prestado por D. Rodrigo foram cruciais para que fosse viável o recrutamento de mão de obra piemontesa, a compra de casulos, a construção de moinhos e a instalação de um filatório que viriam, de facto, a garantir o sucesso desta indústria em Chacim nas últimas décadas do século XVIII e primeiras décadas do século XIX. ${ }^{12}$

Quando avaliamos o papel que mais tarde viria a desempenhar na promoção de instrumentos destinados a uma melhor utilização dos recursos naturais e do capital humano, quer para o território continental de Portugal, quer para os domínios do Brasil, resulta evidente a analogia de preocupações já expressas durante a missão diplomática em Turim. E é interessante notar que, nas diversas situações e momentos em que sentiu o impulso para escrever sobre temas de fomento produtivo, seja na agricultura, seja na indústria, as suas reflexões foram sempre servidas por um conhecimento avançado dos fundamentos científicos e condições tecnológicas indispensáveis à concretização desse objetivo de "criar e fundar solidamente" atividades económicas sustentáveis e competitivas. A riqueza da sua biblioteca em obras de ciência pura e aplicada demonstra bem que a ciência não era para $\mathrm{D}$. Rodrigo um mero passatempo ou curiosidade, nem simples pretexto para erudição ilusória, mas sim o alicerce seguro das suas propostas de desenvolvimento económico.

12 Cf. COUTinHO R. S., Apresentação de José Maria Arnaud a Ayres de Sá e Melo, Secretário de Estado dos Negócios Estrangeiros, in ibid, 132-135. 
A emulação suscitada pelo êxito de algumas atividades económicas na região do Piemonte é especialmente visível nas Reflexões politicas sobre os motivos da prosperidade da agricultura neste país, que servem a fazer ver praticamente as vantajosas consequências dos sábios princípios adoptados (1789). ${ }^{13}$ Neste texto, D. Rodrigo procede de forma metódica e bem sistematizada à identificação dos fatores de prosperidade agrícola no Piemonte, discorrendo sobre eles de uma forma que deixa perceber as influências doutrinais e teóricas na formação do seu pensamento económico. Vale a pena, por isso, determo-nos um pouco mais na narrativa que serve estas Reflexões.

O primeiro motivo que D. Rodrigo aponta como fator de sucesso da agricultura no Piemonte é a natureza do imposto territorial. Merece-lhe aplauso a realização de um cadastro da propriedade que serviu de base ao cálculo da renda líquida dos bens territoriais e à fixação de um imposto único de $20 \%$ sobre o valor de tal renda estimada. Tratava-se de um imposto direto único que evitava a cobrança adicional de dízimos, comendas e tributos de qualquer espécie tradicionalmente associados à propriedade do clero e da nobreza. A sua total concordância com este modelo de taxação, "o mais doce e o mais favorável à agricultura", ${ }^{14}$ decorre certamente da aceitação dos preceitos sobre política fiscal presentes na literatura

13 Incluídas in COUTINHO R. S., Textos políticos, económicos e financeiros, Tomo I, 141-149. Apesar de se terem mantido inéditas na língua em que foram escritas, estas Reflexões mereceram a atenção de autores contemporâneos e, conforme esclareceu Andrée Diniz Silva na nota que acompanha a edição em português na coletânea que temos vindo a utilizar, foram objeto de publicação em inglês, sob iniciativa de Arthur Young, nos Annals of Agriculture, 1791, vol. XV, 517-537, com o título "Reflections on the agriculture of Piedmonte"; em italiano, "Riflessi sull'agricultura del Piemonte", in Opusculi Scelti sulle Scienze e sulle Arti, 1792, vol. XV, 164-175; e em francês, in Arthur Young, Le cultivateur anglais, Paris, 1800-1801, tomo XV, 161-175. As notas elogiosas feitas por Arthur Young (um dos mais reputados escritores britânicos sobre temas de agricultura da $2 .{ }^{a}$ metade do século XVIII) a D. Rodrigo de Sousa Coutinho atestam bem da estatura intelectual e prestígio internacional do embaixador português.

14 Ibid, 143. 
fisiocrática francesa, que D. Rodrigo conhecia bem através da leitura das obras de Dupont de Nemours, Mirabeau, François Quesnay e Mercier de la Rivière, presentes nas estantes da sua biblioteca.

O segundo motivo que assinala para explicar a prosperidade piemontesa é a facilidade e abundância de estradas, numa óbvia evocação da relevância dos sistemas de comunicação para a formação do mercado interno e valorização dos bens produzidos sem acréscimo de custos de transação.

Os três restantes motivos referem-se de forma articulada à estratégia e aos instrumentos de investimento realizado na região do Piemonte. Com efeito, para além de se congratular com os incentivos dados a setores cruciais para a dinamização da agricultura (prados artificiais e sericultura), com a prática de uma taxa de juro reduzida (3\%) para empréstimo de capitais usados na agricultura, D. Rodrigo destaca a circunstância de não terem sido aplicados capitais em atividades improdutivas e de se ter privilegiado a opção deliberada de capitalização do setor agrícola.

Mas a parte mais interessante destas Reflexões políticas é a secção final na qual D. Rodrigo lamenta que tudo o que se passa no Piemonte não tenha correspondência ou reflexo no caso português. A grande multiplicidade de impostos existentes em Portugal, as dificuldades provocadas pelo regime de propriedade e a ausência de investimento produtivo na agricultura inviabilizavam quaisquer ganhos de prosperidade neste setor. Daí decorria a razão de ser da sua apologia piemontesa: que ela servisse de exemplo ao que teria de ser feito em Portugal, em benefício do crescimento da riqueza nacional. ${ }^{15}$

15 Sobre este tipo de processos de emulação política baseados na aceitação e adaptação de ideias económicas em contextos nacionais distintos, cf. REINERT S. A. (2011), Translating Empire. Emulation and the Origins of Political Economy. Cambridge MA and London: Harvard University Press. 
Para além da agricultura e da indústria, cujo desenvolvimento dependia da emulação de boas práticas registadas noutros países europeus, D. Rodrigo de Sousa Coutinho ocupou-se também em Turim da promoção das relações comerciais de âmbito bilateral. O Discurso sobre o comércio de Itália relativamente ao de Portugal $(1784)^{16}$ inicia-se - como sempre acontece nos seus textos de maior fôlego analítico - com considerações de âmbito geral sobre a importância do desenvolvimento do comércio externo, que resume em dois princípios fundamentais:

"1. ${ }^{\circ}$ Que a nação que faz o mais vantajoso comércio é aquela que a troco das suas manufacturas, ou de géneros de luxo e comodidade compra géneros da primeira necessidade para o sustento, géneros para manufacturar, ou sinais representativos da riqueza das nações.

2. ${ }^{\circ}$ Que aquela nação faz o comércio mais desvantajoso a qual compra géneros de luxo, e manufacturas a troco de géneros para o sustento da vida, dos géneros em bruto que hão-de ser manufacturados, e de sinais representativos da riqueza com que se paga a sua balança". ${ }^{17}$

Deste enunciado merece ser realçado o pragmatismo típico de um autor que, não obstante a leitura de obras ilustradas de economia política, nas quais pudesse transparecer a defesa das vantagens absolutas do comércio internacional (independentemente da natureza dos géneros que eram objeto de transação), não esquece o objetivo de longo prazo de equilíbrio da balança de comércio. Em apoio destes princípios genéricos, D. Rodrigo de Sousa Coutinho poderia

16 Incluído in COUTINHO R. S., Textos políticos, económicos e financeiros, Tomo I, 95-112.

${ }^{17}$ Ibid, 100. 
citar diversos autores presentes na sua biblioteca, designadamente, Anderson, Arnoud, Child, Davenant, Decker ou Postlethwayt. Ou seja, poderia socorrer-se dos argumentos veiculados pela literatura tardo-mercantilista que nunca perdeu o sentido dos interesses próprios que as nações procuram salvaguardar.

Mas deverá acrescentar-se que, no desenvolvimento do seu raciocínio sobre as formas de garantir o equilíbrio da balança de comércio, Sousa Coutinho nunca deixa de sublinhar o carácter meramente representativo dos metais preciosos, não caindo na armadilha mercantilista de identificar a sua acumulação com os verdadeiros mecanismos de criação da riqueza. Neste sentido, chega mesmo a considerar que "pode a exportação parcial deste sinal [representativo da riqueza] ser útil enquanto nos trouxer géneros que depois de manufacturados possam trazer depois uma mais forte importação". ${ }^{18}$

Nas considerações de ordem geral que faz sobre o tema do comércio externo e da balança de comércio, D. Rodrigo destaca ainda o papel de uma marinha mercante nacional e das feitorias ou cônsules comerciais, na sua qualidade de agentes responsáveis pela dinamização de acordos de comércio. E, como seria de esperar, a parte mais substancial do Discurso é dedicada à descrição da realidade e à expectativa sobre as potencialidades das relações comerciais entre Portugal e os estados de Itália. Assim cumpria o seu papel como agente diplomático interessado no estreitamento dos negócios bilaterais.

Nas entrelinhas das observações e propostas de D. Rodrigo de Sousa Coutinho perpassa uma preocupação com as dificuldades dos comerciantes portugueses enfrentarem as vicissitudes da concorrência e as exigências técnicas das operações de comércio externo. Esta era uma preocupação igualmente partilhada por outros autores que, na mesma época, consideravam que os negociantes portugueses

18 Ibid, 99. 
não dispunham de instituições capacitadas para a modernização do comércio externo (designadamente nos domínios técnicos da contabilidade, banca e seguros) e que estariam demasiado presos às rotinas de um comércio colonial protegido ou exclusivo e pouco ou nada capacitado para lidarem com os riscos inerentes ao jogo competitivo.

Do conjunto de textos escritos em Turim, o único que conheceu letra impressa em vida do autor (para além das já referidas traduções das Reflexões sobre a prosperidade da agricultura do Piemonte) foi o Discurso sobre a verdadeira influência das minas de metais preciosos na indústria das nações que a possuem, e especialmente da portuguesa (1789). ${ }^{19}$ Trata-se de um curto mas relevante discurso no qual D. Rodrigo de Sousa Coutinho procura demonstrar a incorreção das teses (nomeadamente de Montesquieu) que sustentavam que as minas de metais preciosos produziam efeitos nefastos no desenvolvimento económico das nações que as possuíam. Admite que a existência de minas de ouro e prata e, consequentemente, o acesso às mercadorias que exerciam as funções de numerário ou de equivalente geral nas trocas, poderiam condicionar negativamente a criação das verdadeiras riquezas produtivas. Todavia, não eram esses fatores, em si mesmos, que determinavam o estado de ruína ou decadência de um reino, obrigado a saldar com metais preciosos a balança comercial deficitária. Para Sousa Coutinho, tal défice tinha origem em deficiências estruturais que a existência de minas apenas ajudava a minorar, "não se podendo justamente culpar as minas de um efeito independente delas". ${ }^{20}$

Neste contexto explicativo, os argumentos de Sousa Coutinho desenvolvem-se em duas direções fundamentais: por um lado, a

19 In Memórias económicas da Academia Real das Ciências de Lisboa, para o adiantamento da agricultura, das artes e da indústria, em Portugal e suas conquistas. Lisboa: Banco de Portugal, 1990, Tomo I, 179-183, dir. edição de José Luís Cardoso (Colecção de Obras Clássicas do Pensamento Económico Português).

20 Ibid, 180. 
explicação das razões históricas que haviam ditado, para Portugal, dificuldades de organização das estruturas de produção e de comércio (a expansão marítima, a união ibérica, o tratado de Methuen, ou seja, o habitual rol de fatores explicativos da decadência portuguesa, tal como era lida nos finais do século XVIII); por outro lado, a explicação analítica das potenciais vantagens da exploração de minas de metais preciosos, designadamente no que se refere ao acréscimo da quantidade de moeda em circulação e consequente diminuição do preço do dinheiro ou juro. Desta forma, criavam-se condições excelentes para a aplicação produtiva dos fundos obtidos pela exploração mineira, os quais, por sua vez, garantiriam a satisfação de necessidades acrescidas de produção e de consumo.

As reflexões que desenvolve não são alheias à situação das minas de ouro do Brasil e à discussão sobre a sua rentabilidade. Porém, não é esse o plano discursivo de D. Rodrigo. Situando-se numa perspetiva abstrata, revela a aceitação das ideias em voga, nalguns círculos de produção de discurso económico, sobre a determinação do valor da moeda e sobre a influência da esfera monetária na esfera real da economia. As obras de Locke, Hume e, sobretudo, o célebre Della Moneta de Galiani, faziam parte da sua biblioteca e terão sido, certamente, importante fonte de inspiração.

Entre a diversidade de textos que escreveu durante a sua estadia em Turim, um dos mais interessantes é, sem dúvida, o Discurso sobre a mendicidade, redigido entre os anos de 1787 e 1788, no qual D. Rodrigo de Sousa Coutinho oferece um bem informado ensaio sobre as origens, causas e medidas políticas destinadas a minorar o peso das classes ociosas em qualquer sociedade. ${ }^{21} \mathrm{Com}$ efeito, é como fenómeno associado à ociosidade que a mendicidade é apresentada, em função de três fatores que lhe dão origem: natureza,

21 Incluído in COUTINHO R. S., Textos políticos, económicos e financeiros, Tomo I, 204-232. 
religião e sociedade. D. Rodrigo explica cada um destes três tipos e dá exemplos sobre o modo como a legislação e a atuação política em diferentes países (França, Inglaterra, Prússia, Províncias Unidas e reinos e repúblicas de Itália) procuravam debelar o problema. Na sua abordagem, afasta considerações de carácter moral ou baseadas em valores ou padrões religiosos e estabelece de forma pragmática os contornos políticos de um problema social e económico que exigia ação governativa firme e determinada.

Se era inevitável aceitar a existência de pessoas ociosas por naturais razões de idade ou saúde, certamente merecedoras de compreensão, assistência e cuidados públicos, o mesmo não poderia ser dito em relação às pessoas que se mantinham ociosas por rotinas ditadas por práticas religiosas que impunham número excessivo de horas e dias de culto e que se reproduziam devido à não existência de incentivos ao trabalho. Quanto à mendicidade ou ociosidade decorrente de causas sociais, Sousa Coutinho separa as situações de criminalidade e vagabundagem das situações de impossibilidade de acesso às fontes de riqueza por razões e obstáculos de carácter institucional e legislativo. E destaca o carácter improdutivo do trabalho prestado pelos servidores do $E \operatorname{stado}^{22}$, recomendando a diminuição de empregados e funcionários públicos, uma vez que "o bem público exige não só que o seu número seja proporcionado às necessidades do Estado, e de nenhum modo excessivo, mas também que nestas mesmas classes se favoreça quanto for possível a reunião do público emprego e do trabalho produtivo em que alguns dos indivíduos poderão empregar-se a benefício geral da sociedade". ${ }^{23}$

22 Nesta matéria terá pesado o contacto com as obras da escola fisiocrática francesa (Dupont de Nemours, Mirabeau, Quesnay) que sustentava a distinção entre a classe que contribuía para a formação do produto líquido e da riqueza (classe dos agricultores) e os restantes setores sociais que se limitavam a adicionar ou reproduzir valores criados no setor agrícola (classe estéril).

23 Ibid, 207. 
A inspiração para as medidas políticas destinadas a extirpar, tanto quanto possível, os males decorrentes da ociosidade e mendicidade, foi certamente colhida em obras relativas à ciência e administração do governo, da polícia e do bem-comum, que possuía na sua biblioteca (von Justi, Bielfeld, Filangieri, de Réal, entre outros). Mas foi Necker quem mereceu de D. Rodrigo de Sousa Coutinho o reconhecimento explícito de ter escrito e atuado de forma mais consistente sobre estas matérias.

Os problemas sociais associados à mendicidade e à ociosidade suscitavam a atenção dos agentes políticos preocupados com a melhoria de funcionamento da sociedade. Todavia, D. Rodrigo procurou um entendimento destes problemas à luz de uma conceção mais geral sobre o papel do trabalho produtivo na formação da riqueza. Neste sentido, a grande figura de autoridade tutelar a quem recorre como inspiração teórica do Discurso sobre a mendicidade é Adam Smith, conforme fica claramente demonstrado no excerto seguinte, que apresenta uma excelente súmula das noções de trabalho produtivo, divisão de trabalho e acumulação de capital, desenvolvidas na Riqueza das Nações:

"É hoje um princípio indubitável em economia política que a riqueza de uma nação é proporcional à quantidade ou soma do seu ânuo trabalho. É ele quem faz produzir a terra e florescer a agricultura, dele depende a indústria e o comércio, finalmente é ele quem distingue a sociedade já civilizada, da informe sociedade que liga entre si os povos caçadores e pastores. Esta quantidade do ânuo trabalho depende ou da habilidade dos que trabalham ajudados por máquinas que multiplicam a produção do trabalho, por uma hábil divisão dos ofícios que poupa a perda de tempo, e por uma abundância do capital que não deixa nenhum braço ocioso, ou da proporção que existe entre o número dos que trabalham e dos que vivem ociosamente à custa dos primeiros. Admitidos 
estes princípios que são verdadeiramente tão claros como os mesmos axiomas geométricos, é evidente que qualquer classe de mendicantes ociosos deve ser muito onerosa à sociedade, pois que diminui a riqueza nacional, não só enquanto não trabalha, mas também enquanto impede aquela acumulação de capital de que depende depois o aumento do mesmo trabalho, dando um contínuo emprego à mais activa indústria”. ${ }^{24}$

O recurso a Adam Smith, com que se encerra esta secção, interpela-nos para uma apreciação do âmbito e significado das leituras que contribuíram para formar o seu pensamento. ${ }^{25}$

\section{A economia nas estantes da biblioteca de D. Rodrigo}

A consulta do catálogo da biblioteca que D. Rodrigo de Sousa Coutinho constituiu em Turim (catálogo esse que terá sido atualizado em 1792), revela o carácter eclético de uma coleção onde não faltam obras clássicas da literatura europeia de todas as épocas, obras de referência da filosofia, arte, religião e história universal, compêndios de direito natural e das gentes e coletâneas de legislação, obras de economia, comércio e finanças, tratados de ciência do governo e da arte de fazer política e, acima de tudo, obras de natureza científica sobre diversos ramos do conhecimento (matemática, física, química, astronomia, história natural, medicina e farmácia e ciências aplicadas à agricultura e indústria). De acordo com o levantamento temático

${ }^{24}$ Ibid, 204-205.

25 O conhecimento aprofundado que Sousa Coutinho tinha da obra de Adam Smith é irrefutável. Como curiosidade, assinale-se que a sua biblioteca incluía 2 edições inglesas (a $2 .^{a}$ e a $3 .^{a}$ edições da obra) e duas distintas edições francesas da Riqueza das Nações, possuindo igualmente a $6^{a}$ edição inglesa da Teoria dos Sentimentos Morais. 
realizado por Luís Miguel Carolino, mais de um terço do total de 1334 títulos da biblioteca correspondem a livros de ciência e tecnologia. ${ }^{26} \mathrm{O}$ assunto mereceu já o devido destaque analítico e deverá ser apenas retido como enquadramento das apreciações relativas aos seus livros de economia, entendida num sentido tão estrito quanto era permitido pelo momento embrionário da constituição desta ciência durante o período em que Sousa Coutinho constitui a sua biblioteca.

A listagem que se apresenta no Apêndice inclui um total de 77 títulos. A delimitação é algo ampla, incluindo obras que não sendo propriamente de economia, são fundamentais para se compreender a emergência da economia política como ciência do mercado, mas também como ciência ao serviço do legislador interessado em acompanhar as diversas áreas de governação. Tais são os casos das obras que possuía de Bielfeld, Ferguson, Filangieri, Raynal, de Réal e von Justi. Todavia, evitou-se um critério demasiado aberto que englobasse livros clássicos do pensamento filosófico e político das Luzes (designadamente as obras de Montesquieu, Rousseau, Voltaire, Beccaria, Burke e Priestley) ou obras de carácter científico aplicado à agricultura e indústria (entre as quais se contava a Encyclopédie de Diderot e d'Alembert) que a sua biblioteca ostentava em grande profusão. ${ }^{27}$

A estante de economia pode não ser tão extensa como as de outras áreas do saber. Porém, a qualidade e significado das obras

26 Cf. CAROLinO L. M., O poder dos livros..., RIHGB, 123.

27 A este propósito, creio oportuno partilhar a sugestão interpretativa de Ana Cristina Araújo, Livros de uma vida. Critérios e modalidades de constituição de uma livraria particular no século XVIII. Revista de História das Ideias, 1999, Vol. 20, 149-185, ainda que aplicada a outro contexto: "A memória dos livros, selectivamente organizada, remete para uma ordem de saberes de alcance prático e funcional, que se distende à medida que a leitura, prioritariamente orientada para temas e motivos muito concretos de estudo, se alarga, como se verá, a outros campos, igualmente reveladores dos interesses da capacidade de actualização e até da sensibilidade do proprietário da livraria” (150). 
que juntou na sua biblioteca é deveras surpreendente. Já atrás se esclareceu a relevância das leituras sobre moeda, sobre balança de comércio, sobre política fiscal, sobre trabalho produtivo e improdutivo, sobre ciência da governação e do legislador, e o modo como tais leituras marcaram a sua opinião fundamentada sobre matérias de regulação económica e financeira.

Merece apontamento adicional a posse de diversas obras sobre tratados de paz e de comércio e as descrições de negócios comerciais realizados por diferentes países, de que é bom exemplo a recolha sistemática feita por Jean Rousset. Este tipo de compilações eram um instrumento de trabalho fundamental para os embaixadores que tinham de cumprir atos de negociação e estabelecer compromissos políticos e responsabilidades mercantis em nome do país que representavam, entendidos como gestos de exercício de vontade soberana. Com efeito, era indispensável o conhecimento da literatura económica e política sobre tratados e balanças de comércio, para uso dos que, encarregues de missões diplomáticas, tinham o superior dever de zelar pelo interesse da sua nação sempre que se tratasse de obter por essa via reais benefícios comerciais recíprocos, ou tão-somente garantir certificação de um alinhamento político externo gerador de segurança na manutenção da soberania territorial e política.

Assim se compreende o destaque que nas estantes da diplomacia tinham as obras relacionadas com este importante domínio de atuação de responsáveis políticos no plano interno e externo. ${ }^{28}$ A D. Rodrigo de Sousa Coutinho, embaixador atento e culto, não escapou esse requisito.

Para além dos temas e assuntos que suscitavam o seu interesse político e profissional, e que exigiam leituras específicas

\footnotetext{
${ }^{28}$ Sobre o tema cf. CURTO D. R. e GONÇALVES P. (2015), Livros dos séculos XVI a XVIII da Biblioteca do Ministério dos Negócios Estrangeiros. Lisboa: Biblioteca Nacional de Portugal e Instituto Diplomático.
} 
e especializadas, D. Rodrigo concebia um sistema coerente de reflexão sobre assuntos económicos, cujos ingredientes teóricos e doutrinais eram enriquecidos pelas influências persistentes ou ocasionais de autores como Condillac, Forbonnais, Galiani, Genovesi, Hume, Melon, Morellet, Necker, Smith e Steuart. São estes, em meu entender, os autores que mais marcaram a formação económica de D. Rodrigo de Sousa Coutinho.

Através dessas leituras surgiam motivos de inspiração para o diagnóstico das causas físicas e morais do atraso económico e para a apresentação de propostas de superação dos entraves que impediam uma plena utilização dos recursos materiais e humanos disponíveis. Todos os autores referidos (aos quais se podem acrescentar os representantes da escola fisiocrática) aceitavam alguma liberdade de ação dos agentes económicos tomados na sua individualidade, sobretudo no que se referia aos mecanismos e instituições relacionadas com o funcionamento do mercado interno. Mas não deixavam de chamar a atenção para a necessidade de acautelar os interesses do bem comum, da sociedade no seu conjunto e do propósito público que deveria sempre nortear quem se preocupava em empreender reformas económicas. ${ }^{29}$

Independentemente do espírito ilustrado que animava mais fortemente alguns dos autores referidos, importa reconhecer algum atavismo na identificação de referências de enquadramento da atuação dos indivíduos num perímetro que não excluía a intervenção pública do Estado. O peso da herança mercantilista era ainda muito grande. 30

29 Sobre este sentido interpretativo da economia política emergente na época das Luzes, cf. PERROT J.-C. (1992), Une histoire intellectuelle de l'économie politique (XVII ${ }^{e}$-XVIII ${ }^{e}$ siècle). Paris: Éditions de l'EHESS.

30 Sobre este tópico cf. CLARK H. C. (2007), Compass of Society. Commerce and Absolutism in Old-Regime France. Plymouth: Lexington Books. 
Estes autores podiam ser lidos e apropriados, na medida em que eram suscetíveis de integrar e incorporar camadas expositivas que se sobrepunham e mesclavam, sem perturbar em demasia a ordem política vigente. Era essa a essência do despotismo ilustrado, e do carácter reformista das mudanças económicas que, porém, lentamente introduzidas, acabariam por perturbar essa mesma ordem estabelecida.

Partiam de uma noção abrangente do comércio, como elemento importante mas não como fator exclusivo do processo de crescimento económico. ${ }^{31}$ A indústria, a par da agricultura, eram setores fundamentais para garantir competitividade externa. E a economia política era a ciência que ajudava a entender como se poderiam criar as condições institucionais requeridas para o efeito, designadamente através de: a) aumento do consumo de bens agrícolas, garantindo acréscimo da procura interna; b) aumento das competências e qualificações do número crescente de população empregue na indústria; e c) facilidades criadas nos circuitos monetários e financeiros que agilizavam as trocas comerciais.

Para os economistas da segunda metade do século XVIII, lidos por D. Rodrigo de Sousa Coutinho, a construção de uma moderna sociedade comercial implicava crescente produção, inovação empreendedora e mudança tecnológica. E, se é verdade que tais requisitos não seriam possíveis sem uma forte dinâmica criada pela iniciativa individual em mercados crescentemente competitivos, era igualmente óbvio que a sua concretização exigia a forte presença e participação do Estado. Quanto mais não fosse, pela necessidade de

31 Sobre os conceitos de comércio e de sociabilidade comercial subjacentes a esta interpretação cf. STEINER P. , Commerce, commerce politique. In CHARLES L., LEFEBVRE F. et THÉRÉ C. (eds.), Le cercle de Vincent de Gournay. Savoirs économiques et pratiques administratives en France au milieu du XVIII siècle. Paris: INED (2011), 179-200; e HONT I. (2015), Politics in commercial society. Jean-Jacques Rousseau and Adam Smith. Cambridge MA and London: Harvard University Press (edited by Béla Kapossy and Michael Sonenscher). 
salvaguardar a segurança indispensável à prossecução de relações mercantis internacionais, em ambiente de rivalidade e conflito. O comércio não era apenas doce e dócil, implicava negociações políticas e conflitualidade militar. ${ }^{32}$

$\mathrm{O}$ apelo crescente à bondade dos interesses e paixões individuais, aos vícios privados geradores de riqueza, só era concebível num contexto discursivo mais amplo em que igualmente se apela à regularidade de relações contratuais, às regras universais de administração e justiça e aos sentimentos morais que presidem à ação humana na busca da satisfação individual. 33

Esta visão corresponde precisamente ao conceito de economia que mais marcou D. Rodrigo de Sousa Coutinho, uma noção que inclui instituições e sociabilidade, pluralidade de motivos da ação humana e criatividade individual. Mas também forças de cooperação e interações institucionais visando a satisfação da utilidade individual, concebida como disponibilidade de desempenho de ações úteis, como um instrumento de realização da felicidade pública.

Assim, a busca de felicidade torna-se no objeto central das decisões políticas do soberano ilustrado que gere um sistema integrado em que a economia política assume papel motor. O soberano não se substitui ao mercado, melhor dizendo, não impede o bom funcionamento da sociedade comercial; pelo contrário, é ao soberano que cabe o papel de equilíbrio entre a vida civil e o bem-estar individual, por um lado, e o bem-comum e a felicidade pública, por outro.

32 Cf. BERRY C. (2005), The Idea of Commercial Society in the Scottish Enlightenment. Edinburgh: Edinburgh University Press, 2013; e Istvan Hont, Jealousy of Trade. International Competition and the Nation-State in Historical Perspective. Cambridge, MA and London: Harvard University Press.

33 Sobre este tópico cf. HIRSCHMAN A. O. (1977), The Passions and the Interests: Political Arguments for Capitalism Before its Triumph. Princeton: Princeton University Press. 


\section{Conclusão}

Os autores que D. Rodrigo de Sousa Coutinho leu - uma dedução facilmente comprovada pela listagem de títulos da sua biblioteca - proporcionaram o contágio e irradiação de ideias e práticas que implicavam uma mudança substancial na economia, sociedade e instituições de antigo regime. ${ }^{34} \mathrm{D}$. Rodrigo e os seus mestres pensadores podiam não saber que estavam a contribuir para mudar o mundo. Mas sabemos hoje reconhecer que efetivamente o fizeram.

Pisavam uma plataforma de entendimento comum: o ceticismo profundo sobre uma visão do mundo construída a partir de noções de fé religiosa e a crença numa ciência secular aberta ao escrutínio de seres racionais e baseada na análise empírica do mundo natural e das sociedades humanas a uma escala global. Sabiam da importância dos códigos de conduta humana e dos sentimentos morais geradores de uma sociedade civil estável e geradora de harmonia entre estranhos. Acreditavam numa sociedade comercial cosmopolita com valores e regras aceites de forma comum, capaz de construir a paz global e a prosperidade, em vez de conflito e rivalidade.

A multiplicidade e variedade de leituras que inspiraram D. Rodrigo de Sousa Coutinho tornam difícil o exercício de classificação do seu pensamento económico e político num compartimento estanque. Porém, convidam a fixar algumas ideias fundamentais que ao longo da sua carreira política procurou valorizar, designadamente: a) defesa das virtudes da riqueza privada como instrumento de construção

\footnotetext{
${ }^{34}$ Sobre a criação das condições intelectuais e políticas para uma nova aclimatação das leituras ilustradas em Portugal na segunda metade do século XVIII, cf. ARAÚJO A. C. (1990), Modalidades de leitura das Luzes no tempo de Pombal. Revista de História, Centro de História da Universidade do Porto, Vol. X, 105-127; DE NIPOTTI C. (2007-2008), O mundo organizado em um catálogo de biblioteca. Conhecimento, livros e pensamento em Portugal no início do século XIX. Arquipélago - História, 2. ${ }^{a}$ série, Vols. 11 e 12, 163-190 (sobre a biblioteca de Marino Miguel Franzini); e SILVA M. B. N. (1999), A Cultura Luso-Brasileira. Da reforma da Universidade à Independência do Brasil. Lisboa: Editorial Estampa (cap. IV - Livros e leitura, 129-182).
} 
da opulência das nações; b) crença nas capacidades de aperfeiçoamento humano, de melhoramento material e de obtenção de níveis acrescidos de prosperidade; c) apologia da presença do soberano ao serviço da economia civil, ou seja: defesa dos atributos da economia política como ciência do legislador.

Poder-se-á sempre questionar se os livros da biblioteca de D. Rodrigo de Sousa Coutinho facultam argumentos definitivos que demonstrem a presença inequívoca e insofismável deste tipo de interpretação. Mas os livros que reuniu em Turim não constituíam uma estante virtual nem ficaram entregues à poeira do esquecimento. Através deles, D. Rodrigo consolidou a sua formação e construiu as bases de uma reconhecida reputação como diplomata, homem de ciência e reformador económico e político. 


\section{APÊNDICE}

\section{Biblioteca de D. Rodrigo de Sousa Coutinho}

\section{Obras de economia}

Indicam-se entre parênteses rectos os nomes de autores não identificados no catálogo da biblioteca e as datas de $1 .^{a}$ edição das obras listadas. No catálogo manuscrito as obras estão divididas por língua de edição e por tamanho, com indicação apenas do apelido do autor. Para este Apêndice optou-se por apresentar as obras por ordem alfabética de apelido, incuindo também o nome(s) próprio(s).

O catálogo integral da biblioteca, a partir do qual foi composto este Apêndice, conserva-se no Arquivo Nacional da Torre do Tombo, Fundo Condes de Linhares, Livro 4, acessível em: http://digitarq. arquivos.pt/details? $\mathrm{id}=4727614$.

Anderson, Adam, An historical and chronological deduction of the origin of commerce. London: 1764 ( 2 vols.).

Arnoud, Ambroise M., De la balance du commerce et des relations commerciales extérieures de la France avec toutes les parties du globe. Paris: 1791 (3 vols.).

Bielfeld, baron de, Institutions politiques. La Haye: 1760-1772 (3 vols).

[Brun, abbé], La France regenérée par la plus juste répartition de l'impôt. Paris: 1789. Carli-Rubbi, Gian Rinaldo, Delle moneta. Mantova: 1754 (3 vols.).

Cerutti, M., Idées simples et précises sur le papier monnaie, les assignats forcés et les biens eclésiastiques. Paris: 1790.

Chalmers, George, Estimate of the comparative strength of Great Britain. London: 1786.

Child, Josiah, New Discourse on trade. London: 1698.

Condillac, Étienne Bonnot, Le commerce et le gouvernement considérés relativement l'un à l'autre. Paris: 1776.

Condorcet, J. A. N. de Caritat, marquis de, Vie de Monsieur Turgot. Berne: 1787.

Condorcet, J. A. N. de Caritat, marquis de, Essai sur l'application de l'analyse de la probabilité des décisions. Paris: 1789

Condorcet, J. A. N. de Caritat, marquis de, Bibliothèque de l'homme public. Paris: 1790 (6 vols.). 
[Davenant, Charles], Discourses on the public revenues and on the trade of England. London: 1698.

[Davenant, Charles], An essay upon the probable methods of making a people gainers in the balance of trade. London: 1700.

[Decker, Mattew], An essay on the causes of the decline of the foreign trade. London: 1750.

Dupont de Nemours, Pierre-Samuel, De l'exportation et de l'importation des grains. Soissons: 1764.

Dupont de Nemours, Pierre-Samuel, Physiocratie ou constitution naturelle du gouvernement. Yverdon: 1769 (6 vols.).

[Dupont de Nemours, Pierre-Samuel], Mémoires sur la vie et les ouvrages de Mr. Turgot. Paris: 1782.

[Du Tot], Reflexions politiques sur les finances et le commerce. La Haye: 1754 (2 vols.).

Ensayo de la sociedad bascongada de los amigos del pais. Vitoria: 1768.

Ferguson, Adam, Essay on the history of civil society. Dublin: 1767.

Filangieri, Gaetano, Scienza della legislazione. Firenze: 1784 (7 vols.).

[Forbonnais, François Véron], Considérations sue les finances d'Espagne. Dresde: 1753.

Forbonnais, François Véron, Eléments du commerce. Leyde et Paris: 1754 (2 vols.).

Forbonnais, François Véron, Recherches et considérations sur les finances de France depuis 1595 jusqu'en 1721. Liège: 1758 (6 vols).

[Galiani, Ferdinando], Dialogues sur le commerce des blés. Londres: 1770.

Galiani, Ferdinando, Della moneta. Napoli: 1780.

Genovesi, Antonio, Lezione di commercio, osia di economia civile. Bassano: 1769 (2 vols.).

Goudar, Ange, Les intérêts de la France mal entendus. Amsterdam: 1756 (3 vols.).

Herbert, Claude-Jacques, Essai sur la police des grains, sur leurs prix et sur les effets de l'agriculture [1753]. Berlin: 1755.

Hume, David, Discours politiques. Amsterdam: 1769.

Hume, David, Essays and treatises on several subjects. London: 1772.

[La Rocque], Établissement d'une caisse générale des épargnes du peuple. Bruxelles: 1786.

Le Clerc, Nicolas Gabriel, Atlas du Commerce. Paris: 1786.

Locke, John, Some considerations of the consequences of the lowering of interest and raising the value of money. London: 1692.

[Maisoncelle, Guillaume Charles de], Situation actuelle des finances de la France et de l'Angleterre. Paris: 1789.

Melon, Jean-François, Essai politique sur le commerce [1734]. Paris: 1761.

Memórias Económicas da Academia Real das Ciências de Lisboa. Lisboa: 1789 (tomo I). 
[Mirabeau, Honoré Gabriel Riquetti (et Quesnay, François)], Théorie de l'impot. Paris: 1761.

Mirabeau, Honoré Gabriel Riquetti, L'ami des hommes. Avignon: 1762 (6 vols).

Mirabeau, Honoré Gabriel Riquetti, De la monarchie prussienne sous Fréderic II. Londres: 1788 (8 vols.).

Mirabeau, Honoré Gabriel Riquetti, Lettres sur l'administration de Mr. Necker. Paris: s/d

Morellet, André (Abbé), Mémoire sur la situation actuelle de la Compagnie des Indes. Paris: 1769 .

Necker, Jacques, De l'administration des finances de la France. Lausanne: 1785 (3 vols.).

Necker, Jacques, Oeuvres. Lausanne: 1786.

[O'Heguerty, Pierre-André], Essai sur les intérêts du commerce maritime. Amsterdam: 1777.

[Pelissery, Roch-Antoine], L'administration politique de Colbert. Amsterdam: 1776.

Postlethwayt, Malachy, Britain's commercial interest. London: 1757 (2 vols.).

Postlethwayt, Malachy, History of the public revenue from the revolution in 1688 to Christmas 1753. London: 1759.

Postlethwayt, Malachy, Universal dictionary of trade and commerce. London: 1774 (2 vols.).

Price, Richard, Appeal to the public on the subject of the national debts. London: 1774 .

Price, Richard, Observations on the nature of civil liberty, the principles of government and the justice and policy of the war with America. London: 1776.

Price, Richard, State of the public debts and finances (...) With a plan for raising money by public loans. London: 1783.

Raynal, Guillaume (Abbé), Histoire philosophique et politique des établissements et du commerce des Européens dans les deux Indes. La Haye: 1774 (7 vols.).

Réal, Gaspard de, La science du gouvernement. Paris: 1765.

Reglamento y aranceles reales para el comércio libre de España a Indias. Madrid: 1778.

Ricard, Samuel, Traité général du commerce. Yverdon: 1784.

[Rivière, Mercier de la], L'ordre naturel et essentiel des sociétés politiques. Paris et Londres: 1767.

Rousset, Jean, Recueil historique d'actes, négotiations, mémoires et traités depuis la paix d'Utrecht jusqu'à présent. Amsterdam et Leipzig: 1732 (21 vols.).

[Savary des Brulons, Jacques] Dictionnaire portatif de commerce. Bouillon: 1770 (4 vols.).

[Sérionne, Jacques Accarias de], Les intérêts des nations de l'Europe, dévelopés relativement au commerce. Paris: 1766 (2 vols).

Sinclair, John, The history of the public revenue of the British empire. London: 1789. 
Smith, Adam, An inquiry into the nature and causes of the wealth of nations [1776]. London: $1778,2 .^{a}$ ed. (2 vols.).

Smith, Adam, An inquiry into the nature and causes of the wealth of nations [1776]. London: $1784,3 .^{a}$ ed. (3 vols.).

Smith, Adam, Recherches sur la nature et les causes de la richesse des nations. Yverdon: 1781 (6 vols.).

Smith, Adam, Recherches sur la nature et les causes de la richesse des nations (notes de Condorcet). Paris: 1791 (4 vols.).

Smith, Adam, Theory of moral sentiments [1759]. London: 1790, 6. ${ }^{\mathrm{a}}$ ed. (2 vols.).

Steuart, James, Inquiry into the principles of political economy, being an essay on the science of domestic policy in free nations. London: 1767 (2 vols.).

[Tolosan, M. de], Mémoire sur le commerce de la France et de ses colonies. Paris: 1789.

Thomas, British negotiations of foreign exchanges. London: 1784.

Ustariz, Geronymo, Théorie et pratique du commerce et de la marine (traduit de l'espagnol). Paris: 1753.

Vasco, Giambattista, Della moneta. Saggio politico. Milano: 1772.

Vasco, Giambattista, Mémoire sur les causes de la mendicité et sur les moyens de la supprimer. Turin: 1790.

von Justi, Johann H. G., Eléments géneraux de police (traduits de l'allemand). Paris: 1769.

Ward, Bernardo, Proyecto económico. Madrid: 1782.

Young, Arthur, Works. London: 1767 (4 vols.).

Zimmermann, E. A., Political survey of the present state of Europe in sixteen tables. London: 1787. 
Isabel Ferreira da Mota Doutorada em História pela Universidade de Coimbra, em cuja Faculdade de Letras exerce funções docentes na área de História Moderna e Contemporânea. Autora de vários estudos no âmbito da História Cultural e Política, tendo recebido em 2004 o Prémio da Fundação Calouste Gulbenkian em História Moderna e Contemporânea atribuído à obra A Academia Real da História: os intelectuais, o poder cultural e o poder monárquico no séc. XVIII (2003), Ed. Minerva Coimbra. É investigadora do Centro de História da Sociedade e da Cultura, membro do Conselho de Redação da Revista de História das Ideias, membro da direção executiva da Biblos: Revisła da FLUC e Académica Correspondente da Academia Portuguesa da História.

Carla Enrica Spantigati Entre 1995 e 2010, como Soprintendente per i Beni Artistici e Storici del Piemonte, coordenou a futela dos bens artísticos e museus piemonteses (Palazzo Carignano, Galleria Sabauda, Armeria Reale, Villa della Regina), acompanhando os respectivos projetos de restauro e valorização. Foi diretora científica do Centro de Conservação e Restauro «La Venaria Reale» dirigindo, entre outros, restauros de obras-primas de marcenaria setecentista e publicando os resultados alcançados. Foi curadora de numerosas exposições: em 2007 participou em La Reggia di Venaria e i Savoia. Arti, guerre e magnificenza, organizou a exposição Da van Dyck a Bellotto. Magnificenza alla Corte dei Savoia (Bruxelas, fevereiro-maio 2009) e a secção Torino para La bella Italia (Venaria 2011). Colaborou em 2010 na exposição vienense Prince Eugene. General, Philosopher, Art Lover, realizando em seguida a exposição Le raccolte del Principe Eugenio condottiero e intellettuale. Collezionismo tra Vienna Parigi e Torino nel primo Settecento (Reggia di Venaria Reale 2012). 
Série Investigação

Imprensa da Universidade de Coimbra

Coimbra University Press

2019 